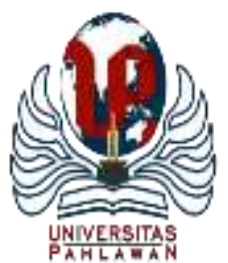

Edukatif : Jurnal Ilmu Pendidikan Volume 3 Nomor 6 Tahun 2021 Halm 4007 - 4013

EDUKATIF: JURNAL ILMU PENDIDIKAN

Research \& Learning in Education

https://edukatif.org/index.php/edukatif/index

\title{
Analisis Kalimat Imperatif Video Dr. Richard Lee di Youtube dalam Pembentukan Personal Branding dan Dimanfaatkan sebagai Bahan Ajar Teks Prosedur
}

\section{Novhia Dwi Payanti ${ }^{1 凶}$, Wienike Dinar Pratiwi ${ }^{2}$, Een Nurhasanah ${ }^{3}$}

Universitas Singaperbangsa Karawang, Indonesia ${ }^{1,2,3}$

E-mail : novhiadwipay@gmail.com ${ }^{1}, \underline{w i e n i k e . d i n a r @ f k i p . u n s i k a . a c . i d ~}^{2}, \underline{\text { een.nurhasanah15@gmail.com }}^{3}$

\begin{abstract}
Abstrak
Penelitian ini dilatarbelakangi oleh keresahan masyarakat akan banyaknya produk-produk kecantikan yang begitu marak di pasaran. Akan tetapi masyarakat belum mengetahui apakah produk tersebut aman atau justru berbahaya jika digunakan dalam jangka waktu yang panjang. Penelitian ini bertujuan untuk mendeskripsikan hasil penemuan jenis kalimat imperatif dalam video Dr. Richard Lee, Mars dalam pembentukan personal branding dan dimanfaatkan sebagai bahan ajar teks prosedur di SMA. Metode yang digunakan dalam penelitian ini adalah metode kualitatif deskripsi. Hasil yang diperoleh dari analisis kalimat imperatif dalam video Dr. Richard Lee, Mars ini adalah ditemukannya 26 kalimat imperatif yang kemudian diklasifikasikan berdasarkan jenis kalimat imperatif menjadi 3 jenis yaitu, 3 jenis kalimat imperatif halus, 11 kalimat imperatif permintaan, dan 12 jenis kalimat imperatif larangan. Jumlah kalimat imperatif yang paling banyak ditemui maka secara tidak langsung telah membentuk personal branding dari Dr. Richard Lee, Mars.
\end{abstract}

Kata Kunci: Bahan Ajar, Kalimat Imperatif, Personal Branding.

\section{Abstract}

This research is motivated by public unrest about the number of beauty products that are so rampant in the market. However, the public does not yet know if the product is safe or even dangerous if used for a long period of time. This study aims to describe the findings of imperative sentence types in Dr. Richard Lee's video, Mars in the formation of personal branding and used as teaching materials for text procedures in high school. The method used in this study was the qualitative method of descriptor. The results obtained from the analysis of imperative sentences in Dr. Richard Lee's video mars is the discovery of 26 imperative sentences which are then classified based on the type of imperative sentences found into 3 types namely, 3 types of fine imperative sentences, 11 imperative sentence requests, and 12 types of prohibition imperative sentences. The most common number of imperative sentences is indirectly the sentence that forms the personal branding of Dr. Richard Lee.

Keywords: Teaching Materials, Imperative Sentences, Personal Branding.

Copyright (c) 2021 Novhia Dwi Payanti, Wienike Dinar Pratiwi, Een Nurhasanah

$\triangle$ Corresponding author

Email : novhiadwipay@gmail.com

DOI : https://doi.org/10.31004/edukatif.v3i3.481

ISSN 2656-8063 (Media Cetak)

ISSN 2656-8071 (Media Online) 
4008 Implementasi Manajemen Berbasis Sekolah dalam Meningkatkan Kualitas di Sekolah Menengah PertamaAulia Diana Devi, Subiyantoro

DOI: https://doi.org/10.31004/edukatif.v3i3.481

\section{PENDAHULUAN}

Bahasa yang dikemukakan Kridalaksana dalam (Chaer 2012:32) adalah lambang bunyi yang arbitrer yang digunakan oleh para anggota kelompok sosial untuk bekerja sama, berkomunikasi, dan mengidentifikasi diri. Bahasa memiliki peran yang penting dalam berkomunikasi. Mengingat akan fungsi dari bahasa itu sendiri adalah sebagai alat komunikasi. Sesuai dengan yang dikemukan oleh Felicia dalam (Astri et al. 2020) bahasa ialah alat yang digunakan untuk dapat berkomunikasi sehari-hari.

Bahasa dalam ilmu linguistik terbagi menjadi bahasa lisan dan bahasa tulis. Bahasa lisan berkaitan dengan segala sesuatu yang dilisankan atau diucapkan, sedangkan bahasa tulis yaitu segala sesuatu yang dituangkan dalam bentuk tulisan atau huruf dan memiliki makna.

Penggunaan bahasa lisan pada zaman modern seperti saat ini sering kita jumpai dalam media sosial. Salah satunya adalah media sosial Youtube. Youtube saat ini tidak hanya digunakan sebagai media hiburan atau media komunikasi saja, akan tetapi Youtube sudah digunakan sebagian orang sebagai lahan pekerjaan yang mampu menghasilkan uang bagi penggunanya. Hingga Maret 2015, pembuat konten di Youtube sudah mengunggah 10.000 video, karena membuat akun atau channel di Youtube dan meraih pelanggan atau penanyangan bisa menghasilkan uang (David, Sondakh, and Harilama 2017). Pada fungsi ini tentu membuat masyarakat terpengaruh dengan apa yang disampaikan oleh pengguna Youtube tersebut.

Sebagai seseorang yang mampu mempengaruhi orang lain tentu harus memiliki bahasa serta susunan kalimat yang baik, mengingat latar belakang penonton yang berbeda-beda. Setiap kalimat yang disampaikan haruslah terdengar jelas sesuai dengan makna yang ingin disampaikannya. Akan tetapi yang sering terjadi pada kenyataannya adalah banyak ditemukannya youtuber yang masih menggunakan bahasa yang dirasa kurang baik dan tidak pantas untuk ditiru. Seseorang dapat mengetahui karakter orang lain dengan melihat akun media sosialnya, dengan kata lain karakter seseorang dapat dibaca melalui aktivitasnya di media sosial, (Tamimy 2017).

Kalimat dalam penggunaan lisan banyak ragamnya, salah satunya adalah kalimat imperatif atau kalimat perintah. Kalimat perintah jika dalam bahasa tulis mampu dibedakan dengan mudah, salah satunya diakhiri dengan tanda seru atau memiliki kata penanda tertentu. Akan tetapi berbeda jika kalimat imperatif itu disampaikan secara lisan. Banyak masyarakat yang masih berpikiran bahwa kalimat imperatif dalam bahasa lisan sering kali diucapkan dengan nada yang tinggi dan terkesan sedikit kasar.

Selain itu, sebagai seseorang yang memiliki pengaruh bagi orang lain haruslah memiliki daya tarik tersendiri. Tujuannya agar lebih mudah dikenal serta diingat oleh orang lain. Daya tarik yang ditanamkan dalam diri seseorang ini disebut dengan personal branding. Saat ini, personal branding dinilai lebih penting dan signifikan pengaruhnya dibandingkan merek perusahan. Hal ini pada dasarnya kita lebih mudah mempercayai individu dibandingkan perusahaan dan kita akan membuat atau menjalin bisnis dengan seseorang yang membuat kita nyaman, Motonya dalam (Imawati, Solihah, and Shihab 2016).

Berdasarkan penjelasan tersebut. maka penulis mengangkat judul penelitian yaitu, "Analisis Kalimat Imperatif Video Dr. Richard Lee, di Youtube dalam Pembentukan Personal Branding dan Dimanfaatkan sebagai Bahan Ajar Teks Prosedur". Adapun rumusan masalah dalam penelitian ini sebagai berikut: (1) Bagaimana klasifikasi jenis kalimat imperatif dalam video Dr. Ricard Lee, Mars di Youtube?, (2) Bagaimana personal branding yang dihasilkan oleh Dr. Richard Lee, Mars dalam akun Youtube Dr. Richard Lee, Mars?, (3) Bagaimana hasil analisis jenis kalimat imperatif dalam video Dr. Ricard Lee, Mars dan dimanfaatkan sebagai bahan ajar teks prosedur di SMA?. Tujuan dari penelitian ini adalah (1) Mendeskripsikan jenis kalimat imperatif dalam video Dr. Richard Lee, Mars di Youtube. (2) Mendeskripsikan personal branding yang dihasilkan oleh Dr. Richard Lee, Mars. (3) Mendeskripsikan hasil analisis jenis kalimat imperatif dalam video Dr. Richard Lee, Mars dan dimanfaatkan sebagai bahan ajar teks prosedur di SMA. 
4009 Implementasi Manajemen Berbasis Sekolah dalam Meningkatkan Kualitas di Sekolah Menengah PertamaAulia Diana Devi, Subiyantoro

DOI: https://doi.org/10.31004/edukatif.v3i3.481

Hasil dari penelitian ini pada akhirnya hanya berupa mendeskripsikan jenis kalimat imperatif yang mana sudah banyak ditemukan pada penelitian lainnya yang serupa. Akan tetapi hasil dari penelitian ini yang dikaitkan dengan personal branding sejauh ini belum ditemukannya referensi yang serupa. Tentunya hasil dari penelitian ini menjadi suatu kebaruan dalam sebuah penelitian.

\section{METODE PENELITIAN}

Metode penelitian yang digunakan adalah kualitatif deskripsi. Dimana hasil dari penelitian ini dijabarkan secara jelas dan rinci oleh peneliti. Objek yang digunakan berupa akun Youtube dari Dr. Richard Lee, Mars. Sesuai dengan apa yang dikatakan Bodgam dan Taylor dalam (Kasmilawati and Agustina 2019) mendefinisikan metodologi kualitatif sebagai prosedur penelitian yang menghasilkan data deskriptif berupa kata-kata tertulis atau lisan dari orang-orang atau perilaku orang yang dapat diamati. Adapun untuk subjeknya adalah kalimat imperatif yang terdapat pada video yang diunggah oleh Dr. Richard Lee, Mars. Menurut Nasution dalam (Sugiyono 2018:223) menyatakan bahwa dalam pemilihan kualitatif, tidak ada pilihan lain daripada menjadikan manusia sebagai instrumen penelitian utama.Pada tahap pengumpulan data peneliti menggunakan metode simak dan catat. Tahap pertama peneliti men-download video yang akan diteliti. Kedua peneliti menonton serta mencatat semua kalimat yang diucapkan oleh Dr. Richard dan kemudian memilah mana sajakah kalimat yang termasuk ke dalam kalimat imperatif dan tahap terakhir peneliti mengklasifikasikan kalimat imperatif tersebut berdasarkan jenis kalimat imperatif yang ditemukan. Sedangkan pada tahap analisis, peneliti menggunakan teknik agih atau teknik dasar Bagi Unsur Langsung (BUL) dengan teknik lanjutan menggunakan teknik ganti. Menurut (Sudaryanto 2015:59) kegunaan teknik ganti adalah untuk mengetahui kadar kesamaan kelas atau kategori unsur terganti atau unsur ginanti dengan unsur pengganti khususnya bila tataran pengganti sama dengan tataran terganti atau tataran ginanti.

\section{HASIL DAN PEMBAHASAN PENELITIAN}

Kalimat adalah bagian ujaran/tulisan yang mempunyai struktur minimal subjek $(\mathrm{S})$ dan predikat $(\mathrm{P})$, dan intonasi finalnya menunjukkan bagian ujaran/tulisan itu sudah lengkap dengan makna (bernada berita, tanya, atau perintah). Adanya struktur minimal S dan P semata-mata menunjukkan bahwa kalimat tidak hanya sekedar gabungan kata yang tidak memiliki kesatuan makna (Finoza 2013:161). Akan tetapi sebuah kalimat harus memiliki pokok pikiran yang lengkap sebagai pengungkap maksud dari penulis. Sedangkan menurut (Alwi 2003) kalimat adalah satuan bahasa terkecil, dalam wujud lisan atau tulisan, yang mengungkapkan pikiran yang utuh.

(Drs. M. Ramlan 2005:39) dijelaskan bahwa berdasarkan fungsinya dalam hubungan situasi, kalimat suruh mengharapkan tanggapan yang berupa tindakan dari orang yang diajak berbicara. Pola intonasi pada kalimat imperatif ditandai dengan (!). Pendapat lain mengenai kalimat imperatif dikemukakan oleh Alwi. Menurut (Alwi 2003:353) berpendapat bahwa kalimat imperatif memiliki ciri formal seperti intonasi yang ditandai nada rendah di akhir tuturan, pemakian partikel penegas, penghalus, dan kata tugas ajakan, harapan, permohonan, dan larangan, susunan inversi sehingga urutannya menjadi tidak selalu terungkap predikatsubjek jika diperlukan, dan pelaku tidak selalu terungkap. Adapun menurut (Rahardi 2005:79) kalimat imperatif mengandung maksud memerintah atau meminta agar mitra tutur melakukan sesuatu sebagaimana diinginkan si penutur. Maka dapat disimpulkan bahwa kalimat imperatif merupakan kalimat yang berisikan perintah atau kalimat yang berisikan harapan agar mitra tutur bertindak sesuai dengan apa diinginkan.

Berdasarkan data kalimat imperatif dalam video Dr. Richard Lee, Mars diperoleh 26 kalimat imperatif. Data yang telah diperoleh tersebut kemudian diklasifikasikan sesuai jenis kalimat imperatif. Menurut (Alwi 2003:353) klasifikasi kalimat imperatif dibagi menjadi tujuh golongan, yaitu kalimat imperatif transitif, 
4010 Implementasi Manajemen Berbasis Sekolah dalam Meningkatkan Kualitas di Sekolah Menengah Pertama Aulia Diana Devi, Subiyantoro

DOI: https://doi.org/10.31004/edukatif.v3i3.481

kalimat imperatif tak transitif, kalimat imperatif halus, kalimat imperatif permintaan, kalimat imperatif ajakan dan harapan, kalimat imperatif larangan, dan kalimat imperatif pembiaran. Akan tetapi, berdasarkan hasil penelitian hanya ditemukan 3 jenis kalimat imperatif dari 7 jenis kalimat imperatif. Adapun jenis kalimat imperatif yang ditemukan adalah, (1) kalimat imperatif halus, (2) kalimat imepratif permintaan, dan (3) kalimat imperatif larangan. Berdasarkan hasil penelitian, penjabaran dari jenis kalimat imperatif yang ditemukan terdiri atas 3 data kalimat imperatif halus, 11 data kalimat imperatif permintaan, dan 12 data kalimat imperatif larangan.

1. Kalimat Imperatif Halus

Pada Bahasa Indonesia juga memiliki sejumlah kata yang dipakai untuk menghaluskan isi kalimat imperatif. Kata seperti tolong, coba, silakan, sudilah, dan kiranya yang sering dipakai untuk maksud itu.

D2/m1 det50, "Atau kalau aktivitas di luar gunakanlah sunblock. Etlis kalian tidak akan lebih hitam.

Biasanya anak-anak usia remaja akan cenderung lebih mudah hitam".

Kutipan tersebut menyatakan perintah untuk masyarakat menggunakan sunblock jika beraktivitas di luar rungan. Kutipan tersebut termasuk ke dalam imperatif halus karena terdapat kata verba dasar yang ditambahkan partikel-lah.

\section{Kalimat Imperatif Permintaan}

Kalimat imperatif juga digunakan untuk mengungkapkan permintaan. Kalimat seperti ini ditandai oleh kata minta atau mohon. Subjek pelaku kalimat imperatif permintaan ialah pembicara yang sering tidak dimunculkan.

D1/det28, "Dan hari ini saya akan buka besar-besaran tentang mafia bodylotion abal-abal dan saya minta tolong dengan kalian kalau kalian mau support saya, kalian bantu saya, kalian terima kasih dengan saya, share video ini."

Makna yang ingin disampaikan pada kutipan tersebut ialah perintah agar masyarakat atau orang yang menonton video tersebut untuk membagikan video yang telah Dr. Richard buat sebagai tanda terimakasih juga bukti dukungan yang diberikan untuk Dr. Richard. Kutipan di atas termasuk ke dalam kalimat imperatif permintaan karena terdapat penanda kata minta/tolong.

3. Kalimat Imperatif Larangan

Kalimat imperatif dapat bersifat larangan dengan adanya kata jangan(lah).

D1/m5 det2, "Jadi better, jangan dipakai, hati-hati dalam penggunaan hidrokuinon seperti ini punya atau cream handbody abal-abal seperti itu ya."

Kutipan tersebut termasuk ke dalam kalimat imperatif yang menyatakan larangan kepada masyarakat dalam menggunakan bahan yang mengandung hidrokuinon atau produk handbody abal-abal, karena sangat berbahaya bagi tubuh. Sesuai dengan (Alwi 2003:357) bahwa yang jadi penanda dari kalimat imperatif larangan ialah adanya kata jangan(lah).

Hasil dari penelitian ini sangat terbatas, karena hanya membahas mengenai jenis kalimat imperatif yang kemudian dikaitkan dengan personal branding. Tidak hanya itu, jenis kalimat imperatif yang ditemukan pun hanya 3 jenis dari ke 7 jenis kalimat imperatif. Tentunya kalimat-kalimat imepratif lainnya yang tidak ditemukan dalam penelitian ini tidak dapat membantu siswa atau guru dalam pembelajaran kalimat imperatif atau teks prosedur lainnya.

Adapun penelitian yang relevan terlebih dahulu dilakukan oleh "Kalimat Imperatif oleh Guru dalam Kegiatan Pembelajaran Bahasa Indonesia di SMP Negeri 13 Kota Magelang.” Hasil dari penelitian tersebut ditemukannya kalimat imperatif sejumlah 1055 kalimat. Hasil penelitian pun disajikan dalam bentuk tabel berdasarkan wujud, struktur, isi, konteks keberadaan, dan fungsi kalimat imperatif. Kalimat imperatif yang digunakan oleh guru yaitu 564 imperatif perintah biasa, 251 imperatif halus, 15 imperatif permohonan, 121 
4011 Implementasi Manajemen Berbasis Sekolah dalam Meningkatkan Kualitas di Sekolah Menengah Pertama Aulia Diana Devi, Subiyantoro

DOI: https://doi.org/10.31004/edukatif.v3i3.481

imperatif ajakan, 4 imperatif harapan, 96 imperatif larangan, dan 4 imperatif pembiaran, (Saputri Audhita Dewanti 2017).

Perbedaan yang terdapat dalam hasil penelitian ini dengan hasil penelitian yang dilakukan Audhita yaitu terletak pada subjek penelitian. Jika Audhita menggunakan guru Bahasa Indonesia sebagai subjek penelitian, sedangkan dalam penelitian ini menggunakan video Dr. Richard Lee yang diunggah di akun Youtubenya. Selain itu yang menjadi perbedaan dari penelitian ini adalah hasil dari penelitian yang dilakukan Audhita tidak dikaitkan dengan bahan ajar, jika hasil dari penelitian ini dikaitkan dengan bahan ajar teks prosedur dan juga personal branding.

Begitu pun dengan hasil penelitian Anak Agung Sri Darmawan dkk yang berjudul "Analisis Kalimat Imperatif dalam Video Tutorial Skincare Clairn Hayes di Youtube dan Relevansinya pada Pembelajaran Teks Prosedur di SMA". Hasil dari penelitian ini menunjukkan bahwa video tutorial skincare Clarin Hayes menggunakan lima macam kalimat impertaif. Kalimat imperatif yang paling banyak ditemukan adalah kalimat imperatif permintaan, terdiri atas 9 kalimat imperatif biasa, 23 kalimat imperatif permintaan, 5 kalimat imperatif pemberian izin, 9 kalimat permintaan ajakan, dan 15 kalimat imperatif suruhan (Darmawanti, Indriani, and Astika 2019).

Perbedaan antara hasil dari penelitian ini dengan penelitian yang dilakukan Anak Agung terletak pada subjek, dan hasil yang ditemukan pada penelitian. Subjek yang digunakan pada penelitian Anak Agung adalah video tutorial skincare Clarin Hayes sedangkan subjek penelitian ini adalah video Tercyduk lagi!Bodylotion abal-abal, ngaku sudah bpom? Mau putih jadi hancur! Kejam-nya helwa dan video tips kulit putih dengan caara yang benar!bukan pakai bodylotion abal-abal!. Perbedaan lainnya dari penelitian ini dengan kedua penelitian yang sudah dijelaskan adalah hasil dari penelitian ini dikaitkan dengan personal branding yang tentunya tidak dibahas dalam kedua penelitian sebelumnya.

Tahap selanjutnya dari penelitian ini adalah mengkaitkan hasil penemuan kalimat imperatif dalam personal branding Dr. Richard Lee, Mars. Menurut Haroen dalam (Soraya 2017) branding adalah aktivitas yang kita lakukan untuk membangun persepsi orang lain terhadap kita mengenai siapa kita. Sedangkan secara harfiah branding adalah sebuah proses atau kata kerja. Sedangkan menurut McNally dalam (Elda 2018) personal branding adalah persepsi dan emosi yang dimiliki oleh orang lain terhadap diri personal seseorang yang mendefinisikan secara menyeluruh pengalaman dalam relasi antarpersonal tersebut. Personal branding dengan kata lain dapat disebut pula sebagai pandangan atau pendapat orang lain terhadap diri kita.

Pada penelitian ini hanya ditemukan kalimat imperatif halus, kalimat imperatif permintaan, dan kalimat imperatif larangan. Maka secara tidak disadari dan tidak disengaja, ketiga kalimat imperatif tersebut telah membentuk personal branding dari Dr. Richard Lee. Selain itu tentunya Dr. Richard memiliki karakter yang tegas, pemberani, dan berbicara sesuai keahliannya. Maka dari itu membuat Dr. Richard Lee mudah dikenal dan diingat orang lain.

Selanjutnya, hasil dari analisis kalimat imperatif dalam video Dr. Richard Lee dapat dimanfaatkan sebagai bahan ajar dalam pembelajaran teks prosedur di Kelas XI Sekolah Menengah Atas (SMA). Menurut Depdiknas dalam (Arsanti 2018) bahan ajar adalah segala bentuk bahan yang digunakan untuk membantu guru/instruktur dalam melaksanakan kegiatan belajar mengajar di kelas, baik berupa bahan tertulis seperti hand out, buku, modul, lembar kerja mahasiswa, brosur, pamflet, wallchart, maupun bahan tidak tertulis seperti video/film, VCD, radio, kaset, CD interaktif berbasis komputer dan internet. Adanya bahan ajar memungkinkan siswa dapat mempelajari suatu kompetensi atau kompetensi dasar secara runtut dan sistematis sehingga secara keseluruhan siswa dapat menguasai semua kompetensi secara utuh. Bahan ajar yang dibuat tentunya disesuaikan terlebih dahulu dengan kurikulum dan juga silabus yang berlaku.

Menurut (Yustinah 2018:2) teks prosedur dapat berisi langkah-langkah atau tahap-tahap yang harus ditempuh untuk mencapai tujuan. Setiap tahapan yang dilakukan berisi informasi antara informasi satu dengan lainnya saling berkaitan. Sedangkan menurut (Pradana 2015) teks prosedur adalah teks yang berisi langkah- 
4012 Implementasi Manajemen Berbasis Sekolah dalam Meningkatkan Kualitas di Sekolah Menengah PertamaAulia Diana Devi, Subiyantoro

DOI: https://doi.org/10.31004/edukatif.v3i3.481

langkah untuk mencapai suatu tujuan. Jadi, dapat disimpulkan bahwa teks prosedur adalah teks yang berisikan langkah-langkah untuk mencapai suatu tujuan.

Pada pembelajaran teks prosedur, kalimat imperatif berfungsi untuk mengarahkan seseorang untuk melakukan sesuatu atau membuat sesuatu tanpa adanya kesalahan. Materi teks prosedur pada silabus mengajarkan tentang struktur, kebahasaan, konjungsi, kalimat imperatif, kalimat interogatif, verba material dan verba tingkah laku. Beberapa hal tersebut terdapat pada video Dr. Richard Lee, Mars. Bahan ajar yang dihasilkan dari penelitian ini berbentuk handout yang di dalamnya berisikan bahan ajar yang berlandaskan pada hasil analisis kalimat imperatif dalam video Dr. Richard. Handout adalah bahan tertulis yang disiapkan oleh seorang guru untuk memperkaya pengetahaun peserta didik, (Majid 2013:175).

Hai semuanya, welcome back to my channel. Jadi saya lagi liatin gambar dari rekan sejawat saya, ini badan yang banyak strectmarknya. Waw, ini karena penggunaan bodylotion abal-abal. Jadi hari ini saya akan bahas tentang bodylotion abal-abal.

Kutipan di atas merupakan salah satu tujuan dari teks prosedur yang dibahas di awal video yang merupakan hasil yang ingin dicapai. Sesuai dengan materi teks prosedur di sekolah yaitu berisikan pernyataan umum, langkah-langkah dan juga tujuan yang ingin dicapai. Konjungsi sebagai syarat teks prosedur yang terdapat pada video Dr. Richard yaitu menggunakan kata satu, kedua, dan pertama. Sedangkan untuk partisipan yang terdapat pada video Dr. Richard ialah kita, kalian, mereka, dan kamu.

\section{KESIMPULAN}

Hasil dari penelitian ini bisa dijadikan sebagai referensi siswa atau guru dalam pembelajaran Bahasa Indonesia khususnya teks prosedur. Selain bahasanya sederhana dan menarik, tentu cara penyampaian Dr. Richard yang menarik, penuh dengan semangat itu membuat pembelajaran jadi terasa lebih menarik dan asik lagi. Hasil dari penelitian ini pula memberikan pesan bahwa dalam proses pembelajaran dapat memanfaatkan teknologi agar pembelajaran lebih bervariatif.

\section{DAFTAR PUSTAKA}

Alwi, Hasan. 2003. Tata Bahasa Baku Bahasa Indonesia. Jakarta: Balai Pustaka.

Arsanti, Meilan. 2018. "Pengembangan Bahan Ajar Mata Kuliah Penulisan Kreatif Bermuatan Nilai-Nilai Pendidikan Karakter Religius Bagi Mahasiswa Prodi Pbsi, Fkip, Unissula." Kredo: Jurnal Ilmiah Bahasa Dan Sastra 1(2):71-90. Doi: 10.24176/Kredo.V1i2.2107.

Astri, Nanda Dwi, Polma Juliati Sinambela, Ayu Yohana Purba, Universitas Prima Indonesia, Bahasa Batak Toba, And Bahasa Minang Kabau. 2020. "Kalimat Imperatif Dalam Bahasa Batak." 9(2).

Chaer, Abdul. 2012. Linguistik Umum. Ke-4. Jakarta: Rineka Cipta.

Darmawanti, Anak Agung Sri, Made Sri Indriani, And Made Astika. 2019. “Analisis Kalimat Imperatif Dalam Video Tutorial Skincare Clarin Hayes Di Youtube Dan Relevansinya Pada Pembelajaran Teks Prosedur Di Sma." Jurnal Pendidikan Bahasa Dan Sastra Indonesia Undiksha 9(2):324-33. Doi: 10.23887/Jjpbs.V9i2.20488.

David, Eribka, Mariam Sondakh, And Stefi Harilama. 2017. "Pengaruh Konten Vlog Dalam Youtube Terhadap Pembentukan Sikap Mahasiswa Ilmu Komunikasi." Acta Diurna 6(1).

Drs. M. Ramlan. 2005. Ilmu Bahasa Indonesia, Sintaksis. Yogyakarta: Cv. Karyono.

Elda, Franzia. 2018. "Personal Branding Melalui Media Sosial, Seminar Nasional Pakar Ke 1.” 2018 15-20.

Finoza, Lamuddin. 2013. Komposisi Bahasa Indonesia. 6th Ed. Edited By I. Setiawan. Jakarta: Diksi. 
4013 Implementasi Manajemen Berbasis Sekolah dalam Meningkatkan Kualitas di Sekolah Menengah PertamaAulia Diana Devi, Subiyantoro

DOI: https://doi.org/10.31004/edukatif.v3i3.481

Imawati, Amanda Vivi, Ayu Wahyuni Solihah, And Mohammad Shihab. 2016. "Analisis Personal Branding Fashion Blogger Diana Rikasari.” Jurnal Ilmu Sosial Dan Ilmu Politik 5(3):175-84.

Kasmilawati, Isna, And Lili Agustina. 2019. "Kalimat Imperatif Dalam Bahasa Lisan Masyarakat Dayak Deah.” Stilistika: Jurnal Bahasa, Sastra, Dan Pengajarannya 4(2):287-96. Doi: 10.33654/Sti.V4i2.996.

Majid, Abdul. 2013. Perencanaan Pembelajaran. Bandung: Pt Remaja Rosdakarya Offset.

Pradana, Putu Gede Ari Pradana. Dkk. 2015. "Pembelajaran Menulis Teks Prosedur Dengan Metode Discovery Learning Di Kelas X Mia 2 Sma Negeri 1 Blahbatuh.” E-Journal Jurusan Pendidikan Bahasa Dan Sastra Indonesia, Undiksha 3(1):341-53.

Rahardi, Kunjana. 2005. Pragmatik: Kesantunan Imperatif Bahasa Indonesia. Jakarta: Erlangga.

Saputri Audhita Dewanti. 2017. "Penggunaan Kalimat Imperatif Oleh Guru Dalam Kegiatan Pembelajaran Bahasa Indonesia Di Smp Negeri 13 Kota Magelang." Universitas Negeri Yogyakarta.

Soraya, Iin. 2017. "Personal Branding Laudya Cynthia Bella Melalui Instagram (Studi Deskriptif Kualitatif Pada Akun Instagram @Bandungmakuta).”Jurnal Komunikasi 8(2):30-38.

Sudaryanto. 2015. Metode Dan Aneka Teknik Analisis Bahasa. Ke-1. Yogyakarta: Sanata Dharma University Press.

Sugiyono. 2018. Metode Penelitian Kuantitaif, Kualitatif, Dan R\&D. Ke-6. Bandung: Alfabeta.

Tamimy, Muhammad Fadhol. 2017. Sharing-Mu Personal Branding-Mu. Jakarta: Visimedia.

Yustinah. 2018. Produktif Berbahasa Indonesia. Jakarta: Erlangga. 